\title{
A case of takotsubo cardiomyopathy in a patient with anaphylaxis treated with epinephrine
}

\author{
Guramrinder S Thind, Prashant Patel, Sandeep Patri, Yashwant Agrawal \\ Department of Internal Medicine, Western Michigan University School of Medicine, Kalamazoo, United States
}

Received: June 1, 2017

DOI: $10.5430 /$ crim.v4n3p66

\author{
Accepted: August 7, 2017 \\ Online Published: August 10, 2017
}

URL: https://doi.org/10.5430/crim.v4n3p66

\begin{abstract}
Takotsubo cardiomyopathy (TTC) is a recently identified transient cardiomyopathy that is usually associated with emotional or physical stress. Catecholamine surge appears to be central to the mechanism of TTC. TTC in the setting of anaphylaxis is rare. We present a case of a 58-year-old female was referred from an outside hospital after being diagnosed with anaphylaxis. She received $0.3 \mathrm{mg}$ epinephrine intramuscularly and $1 \mathrm{mg}$ intravenously. Upon admission to our hospital, she was complaining of chest pain. EKG done in the outside hospital showed ST elevations in the anterior leads but the EKG done at our hospital was normal. She had to be intubated in view of impending airway obstruction. She was subsequently started on epinephrine infusion in the intensive care unit for hypotension. She was found to have elevated troponins that trended up. An echocardiogram performed on day 3 revealed a left ventricular ejection fraction of $25 \%$ and apical hypokinesis suggestive of TTC. Cardiac catheterization was initially deferred in view of a history of dye allergy. A nuclear stress test was done instead that revealed reversible ischemia in anteroseptal regions. Cardiac catheterization was performed eventually with pre-medication that showed a near-normal coronary circulation. A repeat echocardiogram performed 6 weeks after discharge showed normal systolic function.
\end{abstract}

Key Words: Takotsubo cardiomyopathy, Epinephrine therapy, Nuclear stress test, Anaphylaxis

\section{INTRODUCTION}

Takotsubo cardiomyopathy (TTC) in the setting of anaphylaxis is rare, but has been reported previously. Most of these reports have been in patients treated with significant epinephrine therapy. Dose-dependent adverse effects of epinephrine on cardiac function have been described, and these are now backed up by recently elucidated elaborate molecular mechanisms. These effects likely have a mechanistic relationship with TTC. Also, various studies have shown coronary microcirculatory disturbances in patients with TTC and the role of nuclear myocardial perfusion imaging in these patients needs further analysis.

\section{CASE PRESEnTAtion}

A 58-year-old female presented with shortness of breath, tightness in the throat, nausea, and vomiting after being stung by a yellow-jacket wasp. She was initially taken to a nearby hospital where she was diagnosed with anaphylaxis and received 1 dose of epinephrine $0.3 \mathrm{mg}$ intramuscularly and 1 dose of epinephrine $1 \mathrm{mg}$ intravenously. Notably, glucocorticoids and antihistamines were not administered at this time. Following epinephrine administration she developed ventricular tachycardia and received one dose of IV $300 \mathrm{mg}$ amiodarone after which she converted into sinus rhythm. She was subsequently transferred to our hospital.

*Correspondence: Guramrinder S Thind; Email: guramrinder.thind@med.wmich.edu; Address: Department of Internal Medicine, Western Michigan University School of Medicine, 1000 Oakland Drive, Kalamazoo, MI 49008, United States. 
An EKG performed prior to transfer showed ST elevation and was found to be hypotensive with a blood pressure of mainly in the anterior leads (see Figure 1). Upon first contact $74 / 56 \mathrm{mmHg}$. in our emergency room, she was complaining of chest pain

A
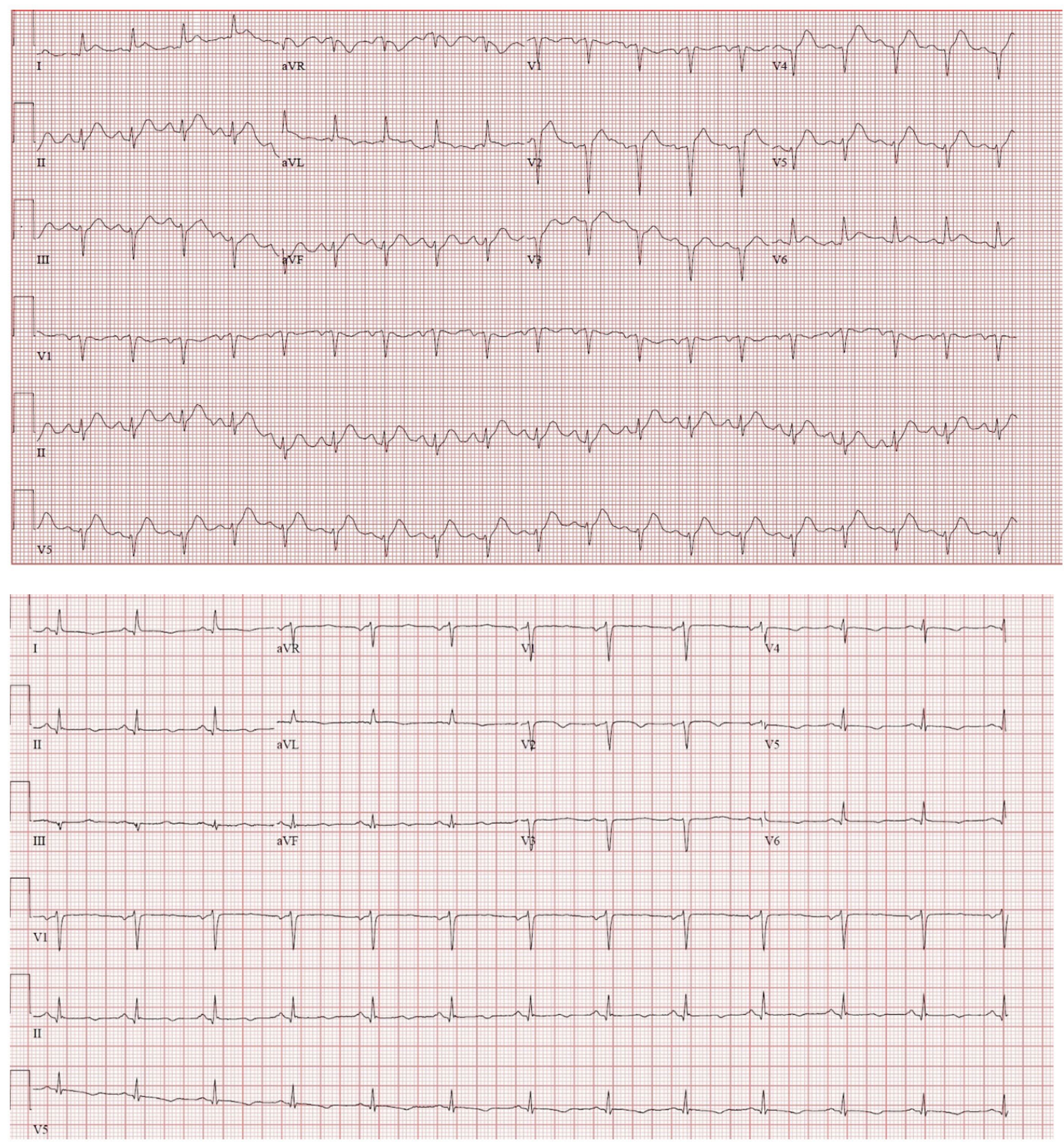

Figure 1. A) Electrocardiogram done at the time of presentation showing ST segment elevation mainly in anterior leads along with sinus tachycardia and left axis deviation. B) Electrocardiogram done at our hospital showing resolution of most ST segment abnormalities as well as a normal rate and axis.

Her physical exam revealed moderate wheezing heard on auscultation. She had to be intubated in view of impending airway obstruction. Her vocal cords were noted to be mildly swollen during the intubation. She was then transferred to the intensive care unit where she received a dose of diphenhydramine $50 \mathrm{mg}$ and famotidine $20 \mathrm{mg}$ intravenously. She was also started on scheduled methylprednisolone $60 \mathrm{mg}$ every 6 Published by Sciedu Press hours and titratable epinephrine infusion for pressor support. There, she was found to have elevated troponins that trended up from $0.14 \mathrm{ng} / \mathrm{ml}$ at the outside hospital to $0.88 \mathrm{ng} / \mathrm{ml}$ at our hospital. The cardiac enzyme trend is presented in Table 1. Other routine laboratory data including a complete blood count and a comprehensive metabolic panel showed no abnormalities. 
Table 1. The trend of cardiac enzymes

\begin{tabular}{|c|c|c|c|c|c|c|c|}
\hline & $\begin{array}{l}\text { Day } 1 \\
\text { 0 }\end{array}$ & $\begin{array}{l}\text { Day } 1 \\
\text { 4h }\end{array}$ & $\begin{array}{l}\text { Day } 1 \\
10 \mathrm{~h}\end{array}$ & $\begin{array}{l}\text { Day } 1 \\
16 h\end{array}$ & $\begin{array}{l}\text { Day } 1 \\
22 \mathrm{~h}\end{array}$ & Day 3 & Day 4 \\
\hline Troponin T (ng/ml) (Normal: < 0.03) & 0.14 & 0.88 & 0.62 & 0.43 & 0.32 & 0.10 & 0.04 \\
\hline CK-MB (ng/ml) (Normal: <6) & 11.4 & 18.9 & 19.5 & 17.7 & & 4.0 & \\
\hline CPK (U/L) (Normal: < 172) & 129 & 197 & 213 & 184 & & 82 & \\
\hline CK-MB index (Normal: $<4 \%$ ) & 8.8 & 9.6 & 9.2 & 9.6 & & 4.9 & \\
\hline
\end{tabular}

At this point, the cardiac ischemia was thought to be likely secondary to demand ischemia in the setting of anaphylactic shock as the patient was considered to be low risk to be having coronary artery disease. Also, the repeat EKG performed at our hospital showed no ST abnormalities. Therefore, emergent cardiac catheterization was not performed in the patient. Patient's hemodynamics stabilized and the epinephrine infusion was gradually tapered off the next day. She was successfully extubated on day 2 . The patient was still complaining

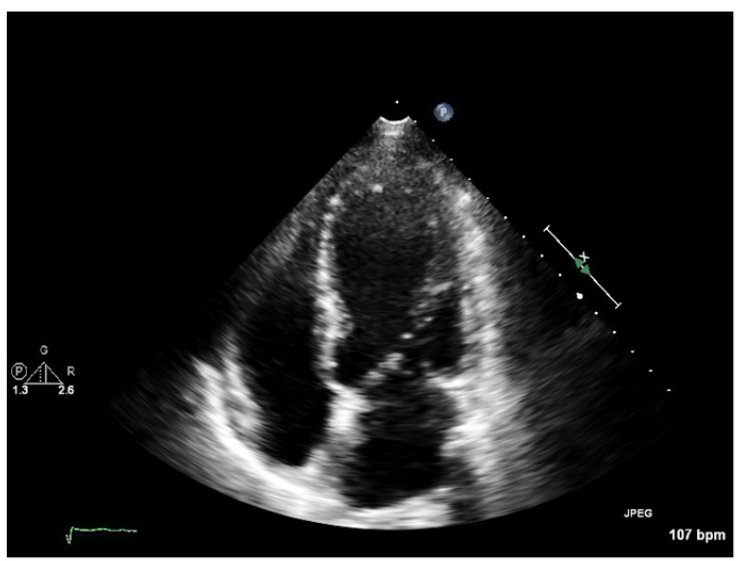

A of intermittent chest pain, however her troponins were now trending down. On day 3, an echocardiogram (ECHO) was performed to assess cardiac function. It revealed reduced systolic function (left ventricular ejection fraction (LVEF) = $25 \%$ ) and apical hypokinesis suggestive of TTC (see Figure 2 ). An elective cardiac catheterization was contemplated to rule out coronary artery disease, but patient had a history of dye allergy.

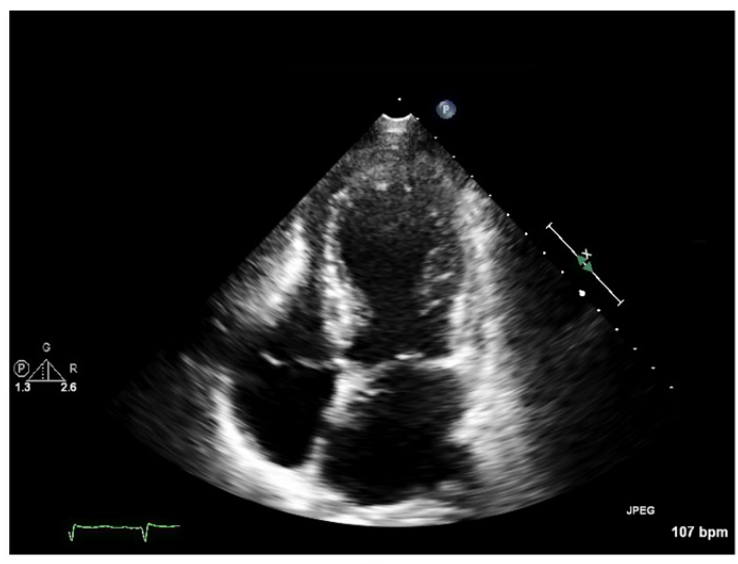

B

Figure 2. An echocardiographic apical four chamber view captured during ventricular end-diastole (A) and ventricular end-systole (B). Figure B demonstrates reduced left ventricular ejection fraction as well as apical hypokineses typical for takotsubo cardiomyopathy.

A nuclear stress test was ordered instead with the intention of ruling out any reversible ischemia. The stress test revealed reversible ischemia in the anteroseptal regions. This finding raised the concern for coronary artery disease and she eventually underwent cardiac catheterization with adequate pre-medication with diphenhydramine $50 \mathrm{mg}$ and dexamethasone $10 \mathrm{mg}$ IV to prevent an allergic response. The study revealed normal coronary circulation except for a $10 \%$ occlusion of the proximal left anterior descending artery, and the diagnosis of TTC was confirmed. Left ventriculography was performed that confirmed the takotsubo morphology.

The determination of normal coronary anatomy with cardiac catheterization firmly established the diagnosis of TTC. Of note, there was no history of any emotional stressor that may have caused the TTC, and epinephrine therapy was considered to be the most likely precipitant. Patient was started on carvedilol and lisinopril and discharged from the hospital with outpatient follow scheduled. Patient was seen 6 weeks after discharge at the Cardiology office, and an ECHO done at that time showed that the left ventricular systolic function has returned to normal.

\section{Discussion}

Takotsubo (stress) cardiomyopathy is now a well-established clinical entity; however, its pathophysiological basis is still being investigated. Some well characterized risk factors have been identified including postmenopausal status and stress. Although stress cardiomyopathy has classically been asso- 
ciated with emotional stress, it is also seen after events that cause significant physical stress e.g. surgery, sepsis, and intracranial bleed.$^{[1]}$

Of the various emerging facets of the pathophysiology, catecholamine (especially epinephrine) surge during the stress event seems to be the central mechanism. In a case series published recently by Abraham et al., iatrogenic stress cardiomyopathy was observed in patients who received epinephrine $(n=6)$ or dobutamine $(n=3) .{ }^{[2]}$ Stress cardiomyopathy has also been reported in patients with anaphylaxis treated with aggressive epinephrine therapy, as well as patients with phaeochromocytoma. ${ }^{[3,4]}$ Most of these cases have been associated with high doses of epinephrine. American Heart Association guidelines recommends a $0.3 \mathrm{mg}$ intramuscular or $0.1 \mathrm{mg}$ intravenous dose of epinephrine for anaphylaxis. ${ }^{[5]}$ In our case and in most other case reports, doses in excess of $1 \mathrm{mg}$ were administered.

A higher incidence of epinephrine overdose in anaphylaxis treatment is reported when the intravenous route of administration is used. In a study by Campbell et al., 301 patients were treated with epinephrine therapy for anaphylaxis. ${ }^{[6]}$ A total of four incidents of overdose were reported, all of which occurred when epinephrine was administered via the intravenous route. Apart from epinephrine therapy, the importance of glucocorticoid and antihistamine therapy in anaphylaxis should not be discounted. Our patient did not receive these in the outside facility. Early administration of these therapies may minimize the dose of epinephrine needed and prevent the need for intubation. It should also be noted that acute coronary syndrome (ACS) has been shown to occur in with severe hypersensitivity reactions. This phenomenon is called Kounis syndrome and is thought to be due to inflammation mediated coronary artery spasm or plaque rupture. ${ }^{[7]}$ Although this was a possible differential in our case, the quick resolution of ST changes and takotsubo pattern of left ventricular dysfunction made this less likely.

The central role of epinephrine in stress cardiomyopathy was reinforced by recent elucidation of the phenomenon "biased agonism". ${ }^{[8]}$ It has been established that, at critically high epinephrine concentrations, beta-2 adrenergic receptor ( $\beta 2 \mathrm{AR}$ ) switches its coupling from Gs protein to the inhibitory Gi protein, thereby resulting in negative inotropic effect. This switch appears to be dependent on the level of $\beta 2 \mathrm{AR}$ phosphorylation, which in turn is facilitated by $\beta 1 \mathrm{AR}$ stimulation by epinephrine. The apical myocardium has been found to have a higher $\beta 2 \mathrm{AR}$ : $\beta 1 \mathrm{AR}$ ratio and that could explain the selective negative inotropic effects of catecholamine surge in the apex.

Another important facet of the pathophysiology of stress cardiomyopathy is microvascular impairment. Studies measuring myocardial perfusion via TIMI myocardial perfusion grade (TMPG) as well as nuclear imaging have demonstrated coronary microcirculatory disturbances. ${ }^{\left[{ }^{9,10]}\right.}$ It has been hypothesized that these microvascular abnormalities may result from increased mechanical wall stress as a consequence of apical ballooning. ${ }^{[11]}$ Nonetheless, these abnormalities may manifest as abnormal nuclear stress tests, as in our case, and stress tests should be interpreted with caution in patients with stress cardiomyopathy.

This case offers important learning points. It is important to recognize that high-dose epinephrine therapy is a possible precipitant of TTC. This is in line with the core pathophysiology of TTC as catecholamine surge during stress is central to its mechanism. In general, epinephrine therapy for anaphylaxis should be dosed with prudence and in accordance to published recommendations. Apart from epinephrine, early administration of glucocorticoids and antihistamines is critical. Finally, nuclear stress test are of limited value in a patient with TTC.

\section{ACKNOWLEDGEMENTS}

All authors contributed to the manuscript as follows. Dr. Guramrinder Singh Thind and Dr. Prashant Patel were part of the primary team who admitted the patient. Dr. Sandeep Patri and Dr. Yashwant Agrawal wer on the Cardiology team, which was consulted for the patient at that time. Hence, all authors were directly involved with patient care. Dr. Thind and Dr. Patel did the literature review and manuscript write-up. Dr. Patri and Dr. Agrawal revised the manuscript critically for important intellectual content. Both authors gave their final approval of the version to be published.

\section{Conflicts of InTEREST Disclosure}

The authors have declared no conflicts of interest.

\section{REFERENCES}

[1] Bybee KA, Prasad A. Stress-related cardiomyopathy syndromes. Circulation. 2008 Jul 22; 118(4): 397-409. PMid:18645066 https: //doi.org/10.1161/CIRCULATIONAHA.106.677625
[2] Abraham J, Mudd JO, Kapur NK, et al. Stress cardiomyopathy after intravenous administration of catecholamines and betareceptor agonists. J Am Coll Cardiol. 2009 Apr 14; 53(15): 1320-5. PMid:19358948 https://doi.org/10.1016/j.jacc. 2009.02 
.020

[3] Khoueiry G, Abi Rafeh N, Azab B, et al. Reverse Takotsubo cardiomyopathy in the setting of anaphylaxis treated with high-dose intravenous epinephrine. J Emerg Med. 2013 Jan; 44(1): 96-9. PMid:22595633 https://doi.org/10.1016/j.jemermed. 201 1.09 .032

[4] Marcovitz PA, Czako P, Rosenblatt S, et al. Pheochromocytoma presenting with Takotsubo syndrome. J Interv Cardiol. 2010 Oct; 23(5): 437-42. PMid:21029177 https://doi.org/10.1111/j.1540-8 183. 2010.00551 . $\mathrm{x}$

[5] ECC Committee, Subcommittees and Task Forces of the American Heart Association. 2005 American Heart Association Guidelines for Cardiopulmonary Resuscitation and Emergency Cardiovascular Care. Circulation. 2005 Dec 13; 112(24 Suppl): IV1-203.

[6] Campbell RL, Bellolio MF, Knutson BD, et al. Epinephrine in anaphylaxis: higher risk of cardiovascular complications and overdose after administration of intravenous bolus epinephrine compared with intramuscular epinephrine. J Allergy Clin Immunol Pract. 2015 JanFeb; 3(1): 76-80. PMid:25577622 https://doi.org/10.1016/j . jaip. 2014.06.007
[7] Fassio F, Losappio L, Antolin-Amerigo D, et al. Kounis syndrome: A concise review with focus on management. Eur J Intern Med. 2016 May; 30: 7-10. PMid:26795552 https://doi.org/10.1016/j. ejim.2015.12.004

[8] Paur H, Wright PT, Sikkel MB, et al. High levels of circulating epinephrine trigger apical cardiodepression in a $\beta 2$-adrenergic receptor/Gi-dependent manner: A new model of Takotsubo cardiomyopathy. Circulation. 2012 Aug 7; 126(6): 697-706. PMid:22732314 https://doi.org/10.1161/CIRCULATIONAHA.112.111591

[9] Elesber A, Lerman A, Bybee KA, et al. Myocardial perfusion in apical ballooning syndrome correlate of myocardial injury. Am Heart J. 2006 Sep; 152(3): 469.e9-13. PMid:16923415 https : //doi.org/10.1016/j.ahj.2006.06.007

[10] Yoshida T, Hibino T, Kako N, et al. A pathophysiologic study of tako-tsubo cardiomyopathy with F-18 fluorodeoxyglucose positron emission tomography. Eur Heart J. 2007 Nov; 28(21): 2598-604. PMid:17921529 https ://doi.org/10.1093/eurheartj/ehm4 01

[11] Akashi YJ, Goldstein DS, Barbaro G, et al. Takotsubo cardiomyopathy: a new form of acute, reversible heart failure. Circulation. 2008 Dec 16; 118(25): 2754-62. PMid:19106400 https: //doi.org/10.1161/CIRCULATIONAHA.108.767012 